\title{
Editor Note on Phylogenetics to Trace Evolutionary Event
}

\section{Luciano Brocchieri}

Department of Molecular Genetics and Microbiology, and Genetics Institute, University of Florida, USA, Tel: 352-273-8131; E-Mail: lucianob@ufl.edu

The Journal of Phylogenetics and Evolutionary Biology volume 4 issue 2, reports a variety of studies from across the Globe investigating how evolutionary events have shaped current population structures and ecological communities.

The study by Mbithe et al. [1] aimed at characterizing sweet potato varieties that can be used as both food and feed under the agricultural context of Uganda. To meet global food demand, mixed crop-livestock systems are the priority of small farmers in the developing countries of sub-Saharan Africa, where alternative staple food like sweet potato is grown. The outcome of this study can be helpful to the farmers for the dual purpose of providing healthier food and better feed by sweet potato production.

The study by Elsaied et al. [2] explored the role of gut microflora in maintaining the health of the fish flathead gray muller (Mugil cephalus) in a Mediterranean estuary, evaluating the diversity of rRNA genes of the gut microflora of both adults and fingerlings. It is the first-ever report of the presence of uncultured thaumarchaeote-like microbes in the fish gut, opening the door to exploring the biological significance of these archea in fish metabolism.

The study by Loyola et al. [3] analyzed the evolution of pandemic Vibrio parahaemolyticus pathogens by a process referred as read accounting. The study assessed the clonal frames of whole genomes, and the likely causes for the observed variability are proposed.
The study by Ruiz-García et al. [4] meticulously reported variability in mitochondrial genes of capybaras (Hydrochoerus hydrochaeris) sampled across the Amazon Basin. Biodiversity in the Amzon basin and its explanations have drawn the attention of naturalists worldwide since 19th century. The authors conclude that it is not easy to identify an explanation for the genetic variability observed across Capybara populations of the Amazon basin since multiple factors can have differentially impacted at different times the genetic structure of these populations.

\section{References}

1. Mbithe MJ, Steven R, Agili S, Kivuva MB, Kioko WF, et al. (2016) Morphological Characterization of Selected Ugandan Sweet potato (Ipomoea batatas L) Varieties for Food and Feed. J Phylogen Evolution Biol 4:163.

2. Elsaied HE, Taleb HTA, Wassel MA, Rashed MAS (2016) Composition of Eukaryotic and Prokaryotic Rrna Gene Phylotypesuin Guts of Adults and Fingerlings of Mugilcephalus, Inhabiting an Egyptian Mediterranean Estuary. J Phylogen Evolution Biol 4:164.

3. Loyola DE, Yañez C, Plaza N, García K, Espejo RT (2016) Genealogy of the Genome Components in the Highly Homogeneous Pandemic Vibrio parahaemolyticus Population. J Phylogen Evolution Biol 4:165.

4. Ruiz-García M, Luengas-Villamil K, Pinedo-Castro M, Leal L, Bernal-Parra LM, et al. (2016) Continuous Miocene, Pliocene and Pleistocene Influences on Mitochondrial Diversification of the Capybara (Hydrochoerus hydrochaeris; Hydrochoeridae, Rodentia): Incapacity to Determine Exclusive Hypotheses on the Origins of the Amazon and Orinoco Diversity for This Species. J Phylogen Evolution Biol 4:166. 